\title{
STRUCTURAL STABILITY AND FATIGUE ASSESSMENTS OF DUAL-AXIS SOLAR TRACKERS USING FINITE ELEMENTS ANALYSIS
}

\begin{abstract}
Abdulla AL-Rashidi
Department of Civil Engineering, Public Authority for Applied Education and Training, Kuwait

*Corresponding Author, Received: 05 March 2020, Revised: 23 March 2020, Accepted: 11 April 2020

ABSTRACT: The use of advanced technologies to increase the amount of solar irradiance received, using solar tracking systems, is an important development that will enhance the efficiency of solar modules' ability to produce energy. However, solar trackers are vulnerable to failure or collapse, due to aerodynamic loads. This study analyses a dual-axis tracking model, using finite elements numerical modelling, to assess its structural stability and fatigue under static and cyclic loads. A rectangular solar tracker, with an area of $27.4 \mathrm{~m}^{2}$ is investigated, using COMSOL Multiphysics 5.3 software. The results demonstrate that the maximum von Mises stress obtained is $92.51 \mathrm{MPa}$, which is less than the yield stress (200 MPa), and that the resulting safety value is 2.16 . The maximum settlement obtained is $19 \mathrm{~mm}$. In addition, the maximum usage fatigue factor obtained is 0.046 . The study therefore concludes that the solar tracker structure satisfies the design requirements of the stability and fatigue criteria. Moreover, it concludes the ground concerned is stable, and exhibits only a slight amount of settlement that falls within the acceptable range, according to geotechnical engineering design.
\end{abstract}

\section{Keywords: Tracking systems; Photovoltaic; Finite element; Stability; Fatigue; Settlement}

\section{INTRODUCTION}

The use of renewable energy is one of the most successful strategies implemented worldwide to obtain energy from free and clean sources, such as the sun and wind. Solar photovoltaic (PV) technology represents a good example for the exploration of the results achieved by the proper use of renewable technologies, such as solar PV technologies using solar tracker systems. Despite the advanced levels this technology has achieved recently, the efficiency and high initial investment costs required remain a considerable challenge for investors, researchers, and other stakeholders in this technology. In the last decade, the use of single and dual-axis tracking systems has played an important role in terms of gaining high amounts of energy, and much research has been conducted to analyse and design various types of solar trackers [1-5]. These studies found that the selfweight of the structure, and wind loads, are the primary forces that affect its stability directly, and hence such structures should be designed and tested to a high level. In addition, the study of the mechanical behaviour of the structures, and the investigation of different wind directions, are also important issues that will assist in selecting the proper design and materials to be used [6,7].

The implementation of tracking systems has achieved tremendous results in Kuwait, in terms of the electricity produced, as evidenced by a number of studies [8-11], which found that the high amounts of energy achieved, which varied between $24 \%$ and $28 \%$, could be more successfully obtained using single and dual-axis tracking systems than fixed tracking systems.

It is important that the soil beneath the structure, and the stability of the structure itself are maintained, in order that optimum use of the solar modules of PV systems are achieved, to receive the maximum amount of solar irradiance possible. Solar tracking systems are also highly affected by stresses induced by wind loads. From an economic viewpoint, the disruption of solar systems, whether partially or totally, has a significant impact on the budget of these types of projects.

The present study employs a fatigue assessment of such a structure, as wind force is one of the main loads affecting solar trackers. It is necessary to investigate the effect of aerodynamic forces, such as cyclic forces that vary in magnitude and direction over time. Fatigue is simply defined as the failure of a metal, due to repeated cycles of stress or strain [12].

This study investigates the stability of a dual-axis tracking solar structure, under static loading, and assesses its fatigue failure criterion under the cyclic loads resulting from wind load. The study was conducted at Boubyan Island in Kuwait; Fig. 1 illustrates the site's location. The study includes an investigation of the ground beneath the solar tracker as a main part of the geometry used in the analysis, since an important and a significant aspect of the design and analysis is the inclusion of 


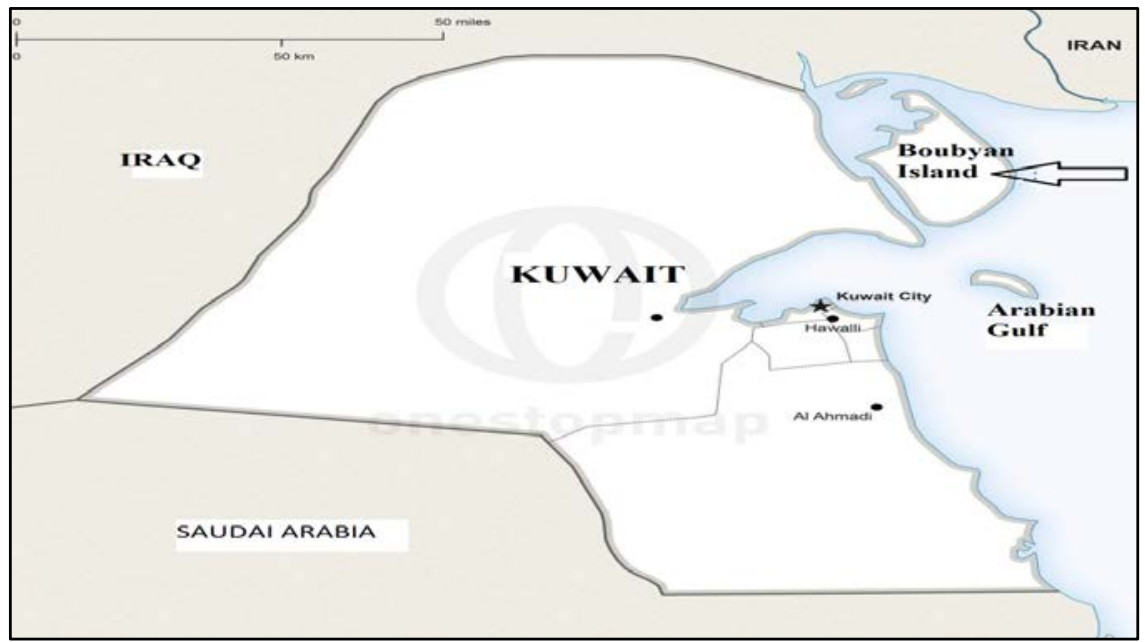

Fig. 1 Location of the Boubyan Island, Kuwait

a geotechnical investigation of the proposed solar tracker's location. This study contributes significantly to the understanding of the economic and technical issues it addresses.

\section{METHODOLOGY}

This study employed COMSOL Multiphysics 5.3 software to conduct an assessment of the structural stability of the solar tracker concerned against wind loading from different directions, and it also conducted a fatigue assessment. In addition, the behaviour of the ground, resulting from the aerodynamic and static loads of the superstructure, was investigated in terms of the stability of the soil beneath the solar tracker. This was tested by evaluating the stresses and strains induced in the soil, together with the maximum amount of soil settlement.

Boubyan, the largest Kuwaiti island, was selected as the site for a PV solar system to be tested. It is located in the northeast of Kuwait, and has an area of $683 \mathrm{~km}^{2}$. The ground of the island is composed mainly of very soft to soft silty clay, with a thickness of $26 \mathrm{~m}$, and a dense to very dense fine sand layer located beneath the clay layer. In general, the ground of Boubyan is flat, with ground surface levels varying from 2.1 to $3.4 \mathrm{~m}$.

For the purposes of this study, a model of a $4 \mathrm{x}$ 4 array dual-axis solar tracker, with an area of 27 $\mathrm{m}^{2}$ was created (Fig. 2) to assess the stability of the structure at this location. In order to determine this, a three-dimensional finite element model was designed and analysed, according to finite element methods. The finite element model was validated using a study conducted by [11]. The results computed concurred with the validated study, and the standard deviation ranged between $5 \%$ to $14.4 \%$, a range that is considered to be acceptable in numerical computational methods science, as it is less than $30 \%$. The graph in Fig. 3 compares the results obtained by the COMSOL Multiphysics 5.3 software, and the case study. The graph is based on five different inclination angles at the maximum von Mises stress criterion.

Table 1 lists the soil properties and strength parameters used in this study. The modulus of elasticity and a Poisson's ratio for the solar modules were set to $3.5 \mathrm{GPa}$ and 0.33 , respectively [11,13]. A linear elastic model was set for the steel and concrete materials, and Mohr-Coulomb model was applied for the soil material.

The main loads in the analysis were the selfweight of the superstructure, and the wind load. The wind load was applied as a boundary load, and the wind speed was set to $40 \mathrm{~m} / \mathrm{s}[11,14,15]$. The wind load magnitudes were determined using the American Society of Civil Engineers approach, and the following equation was used $[11,16]$ :

$$
\mathrm{q}_{\mathrm{z}}=0.613 \mathrm{~K}_{\mathrm{z}} \mathrm{K}_{\mathrm{zt}} \mathrm{K}_{\mathrm{d}} \mathrm{V}^{2} \mathrm{I}
$$

Table 2 provides the detailed inputs of the wind load used in this study. The boundary condition applied was considered to be a fixed constraint to the bottom of the ground, and a roller constraint to the ground at the other boundaries. A second order displacement tetrahedral type mesh was applied, consisting of 31,523 elements; the mesh is shown in Fig. 4. It should be noted that one of the main challenges of this study was the mesh size, which was relatively large, and was therefore timeconsuming, nevertheless it facilitated the use of appropriate methods, and the achievement of more accurate results.

\section{RESULTS AND DISCUSSION}

In engineering, fatigue assessments are important when considering the stability of many different types of steel structures, specifically those exposed to varying loads, such as aerodynamic loads. 


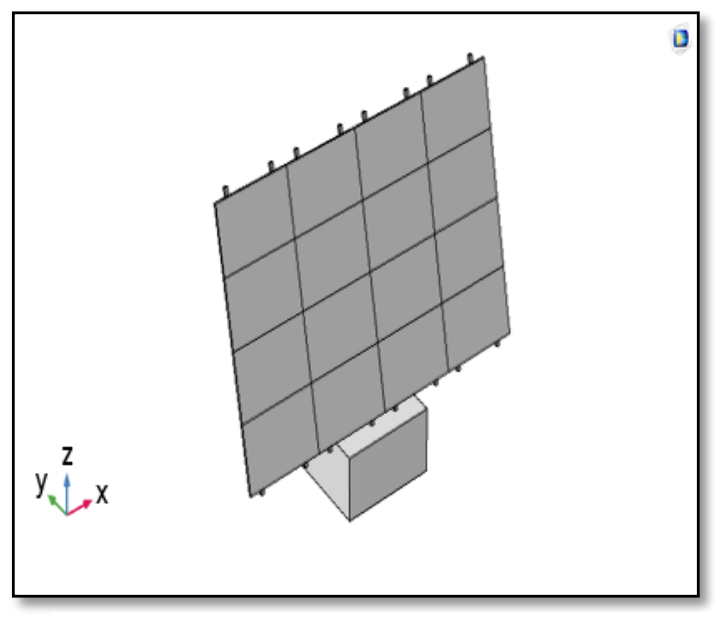

Fig. 2 Geometric configuration of the solar array

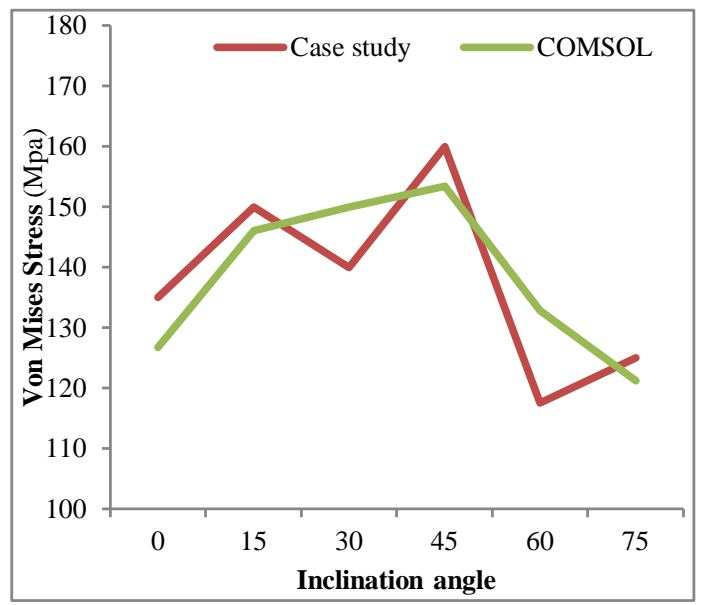

Fig. 3 Validation of the proposed model

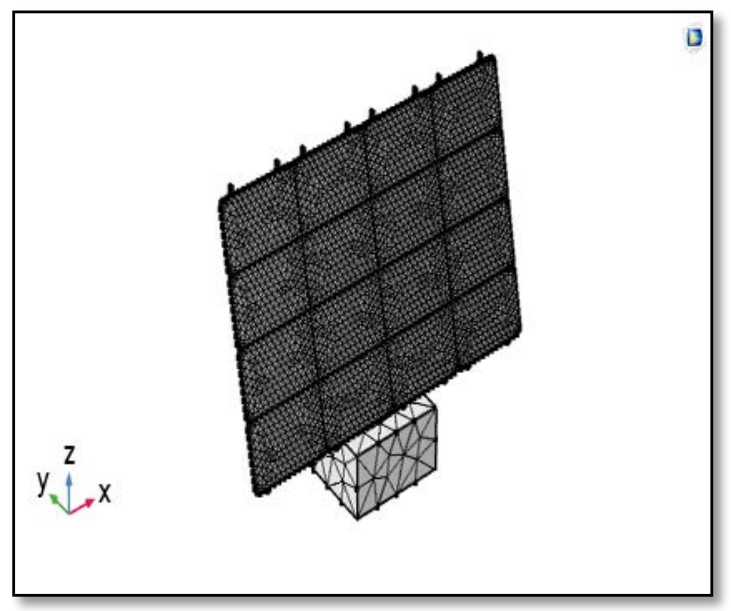

Fig. 4 Finite elements mesh.

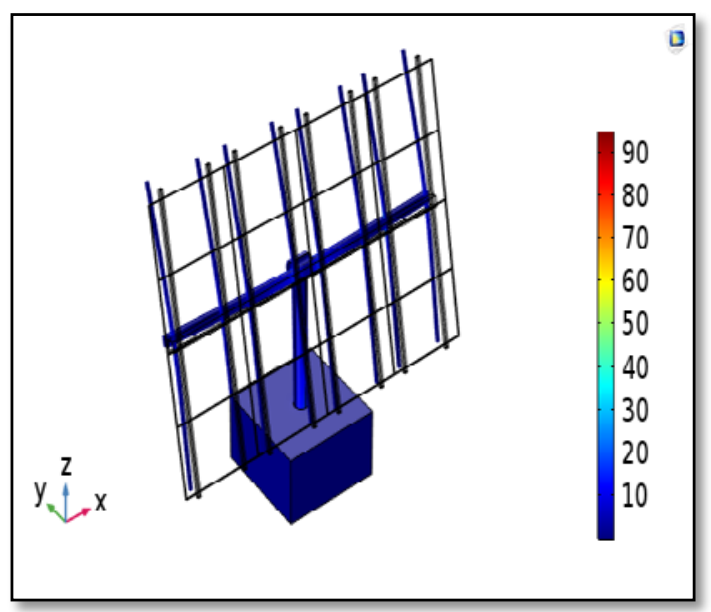

Fig. 5 von Mises stress (MPa) on the structure

Table 1 Soil properties (Source: [17])

\begin{tabular}{cccccccc}
\hline Layer & Classification & w\% & Gs & $\begin{array}{c}\text { Unite weight } \\
\mathrm{kN} / \mathrm{m}^{3}\end{array}$ & $\begin{array}{c}\mathrm{Cu} \\
\mathrm{kN} / \mathrm{m}^{2}\end{array}$ & $\begin{array}{c}\mathrm{C}^{\prime} \\
\mathrm{kN} / \mathrm{m}^{2}\end{array}$ & $\phi^{\prime}$ \\
\hline Top Layer & CL-CI & 35.4 & 2.66 & 18.1 & $15-31$ & 0 & 30 \\
Bottom Layer & Very silty Sand & 20.4 & 2.6 & 20.3 & - & 0 & 36 \\
\hline
\end{tabular}


The stress life, strain life, and crack initiation approaches are the methods most commonly employed for investigating the behaviour of engineering materials against fatigue criterion [1820]. In this study, the stress life (S-N) method was employed to investigate the fatigue life of the solar tracker structure. This method essentially determined the relationship between the stresses induced in the solar structure in the elastic range with the fatigue life.

In this analysis, the weight of the solar tracker structure, and the loads induced by the wind, of varying magnitudes and directions, were considered. In order to calculate the fatigue life, the wind load was assumed to possess a constant amplitude, with a constant maximum stress induced under the cyclic loadings.

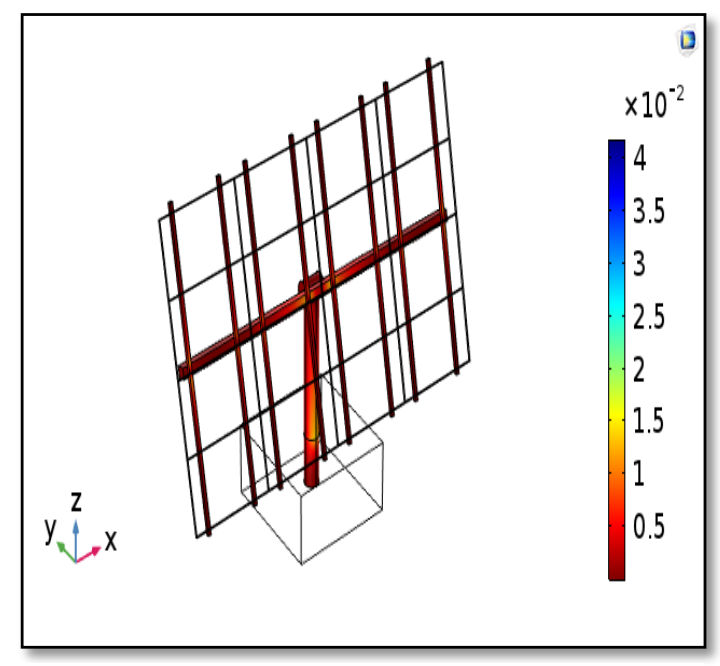

Fig. 6 Usage fatigue factor

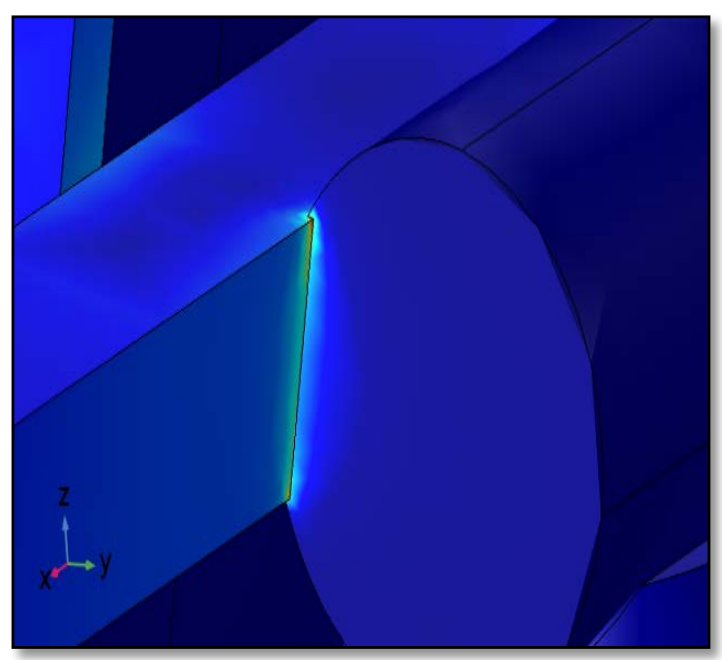

Fig. 7 Maximum usage fatigue factor
The life fatigue was determined using COMSOL Multiphysics 5.3 software, and the S-N curves for the structural steel material were taken from the Atlas of Fatigue Curves, ASM International [21].

The investigation of the behaviour of the dualaxis solar tracking system was conducted by determining the maximum stresses and strains at the static loading and the cyclic loading, in order to determine the stability and fatigue criterion.

Table 3 lists the results obtained from the numerical modelling analysis. Fig. 5 presents the von Mises stresses over the solar tracking system. As illustrated, the maximum stress value obtained was $92.51 \mathrm{MPa}$. This value was induced by a wind load blowing from a southerly direction, with the inclination angle of the solar tracker at $75^{\circ}$. The safety factor was 2.16, and the solar tracker was therefore deemed to be safe and stable under the loads applied. It was apparent that the maximum stresses and strains occurred at the joint connection between the main beam supporting the solar panels and post. This was to be expected, as the joints are the weakest and most critical regions, according to basic structural engineering principles.

The maximum equivalent strain obtained was equal to $1.36 \mathrm{E}-3$, which clearly indicated that the behaviour of the solar tracker under the static loading was in the elastic region, with slight effects caused by the loads applied, in terms of the deformation of the solar tracker's elements.

Fig. 6 presents the usage fatigue failure obtained. A value of 0.046 was recorded at the critical region where the maximum stresses and strains occurred (Fig. 7). In other words, the proposed solar tracker was able to withstand more than 21,700 cycles, before achieving the failure stage caused by the cyclic aerodynamics loads.

According to [22], the values obtained indicate a safe design, in terms of fatigue criterion. Moreover, there was a clear agreement in terms of the critical regions of the solar tracker that are highly vulnerable to failure. Therefore, there should be an emphasis on, and consideration of, these regions during the design and material selection stages.

As previously stated, the super structure, which was primarily the solar tracker, was affected by its own weigh and by the wind-induced stress. The mechanism of the load transfer from the super structure to the ground indicated a need for further investigation of the ground, in order to evaluate the 


\begin{tabular}{ccc}
\hline $\begin{array}{c}\text { Basic wind speed } \\
\text { Velocity pressure }\end{array}$ & $\mathrm{V}=40 \mathrm{~m} / \mathrm{s}$ & 3 second gust wind speed for Kuwait \\
exposure coefficient & Exposure $\mathrm{D}$ & Open area \\
$\begin{array}{c}\text { Topographic factor } \\
\text { Wind directionality }\end{array}$ & $\mathrm{Kzt}=1.0$ & ASCE standard (Section 6.5.7.2) \\
Velocity pressure & $\mathrm{Kd}=0.85$ & ASCE standard (Section 6.5.4.4), Table 6.4 \\
exposure coefficient & $\mathrm{Kz}=0.85$ & ASCE standard (Section 6.5.6.6), Table 6.3 \\
Importance factor & $\mathrm{I}=1.0$ & \\
\hline
\end{tabular}

Table 3 Results obtained from the software programme

\begin{tabular}{ll}
\hline \multicolumn{1}{c}{ Criterion } \\
Maximum von Mises stress (MPa) & 92.51 \\
Maximum displacements (mm) & 19 \\
Equivalent strains & $1.36 \mathrm{E}-3$ \\
Factor of safety & 2.16 \\
\hline
\end{tabular}

stability of the solar tracker in this location. In terms of geotechnical design, the loads transmitted from the super structure to the soil layers would have insignificant effects on the soil layers. This was apparent in the degree of soil settlement indicated beneath the solar tracker's footing, which was equal to $19 \mathrm{~mm}$ for the critical situation.

However, the effects of the high wind speed should not be ignored, since extreme wind speeds would have a serious effect on the solar tracker's structure. Therefore, preventative actions should be employed, such as utilising a defensive position, in which the solar tracker is at a $0^{\circ}$ inclination angle, which would be beneficial for reducing the surface area exposed to the wind direction, and would eventually decrease the aerodynamic stresses induced.

\section{CONCLUSION}

The use of solar PV systems, equipped with tracking systems, and with the ability to change their orientation and direction to follow the sun has increased significantly, since these types of systems are a valuable means of harvesting the maximum amount of solar radiation. The stability of such solar tracker structures is an important issue that should be considered in their design, since they are highly prone to failure and/or collapse, due to aerodynamic loads that vary in terms of magnitude and direction over time. These types of loads cause what is known in engineering terms as fatigue failure.

This study investigated the behaviour of a dualaxis solar tracker at Boubyan Island in Kuwait, due to aerodynamic loads, by conducting numerical modelling methods, using finite element software. The maximum stress recorded was $92.51 \mathrm{MPa}$, a value that was less than the ultimate stress of the structural steel (200 MPa) tested in this study.

In terms of the safety factor, a 2.16 value was obtained, which was an acceptable value for such structures, as it occurred at the worst or most critical location. The maximum stresses and strains obtained were recorded at the joint connection between the main beam and the post, which suggested that consideration should be given to this region at the design stage, and that ductile and strong materials should be used. In addition, a relatively a small amount of equivalent strain was determined (1.36E-3), indicating that a small amount of deformation that had occurred in the steel materials, without affecting their elastic properties. The ground was found to be stable and safe, as indicated by the maximum settlement of the soil layers, which was $19 \mathrm{~mm}$. This fell within an acceptable range, and indicated that the effect of the self-weight of the structure had a greater effect than the aerodynamics loads. However, the effect of high wind speeds should not be ignored, and it is therefore extremely important that a defensive position mode is applied to solar tracking structures whenever there is a risk of high wind speeds.

This study would be an important and a significant part of designing and analysing by means of geotechnical investigation of the proposed solar tracker. Moreover, this study will have a significant contribution to the knowledge in different of economic and technical issues. 


\section{REFERNCES}

[1] Mihailidis A., Panagiotidis K., and Agouridas $\mathrm{K}$, Analysis of solar panel support structures, 3rd ANSA \& META International Conference, Halkidiki, Greece, 9-11 Septamber, 2009.

[2] Mathew A., Biju B., Mathews N., and Pathapadu. Design and Stability Analysis of Solar Panel Supporting Structure Subjected to Wind Force , International Journal of Engineering Research \& Technology (IJERT), Vol. 2, Issue 12, 2013, pp.559-565.

[3] Baetu G., Teleman C., Axinte E., and Roşca V., Numerical Simulation of Wind Action on a Solar Panels Array for Different Wind Directions, Bulletin of the Polytechnic Institute of Iasi - Construction \& Architecture Section, Vol. 63, Issue 4, 2013, pp. 9-20.

[4] Stathopoulos T., Zisis I., and Xypnitou E., Local and overall wind pressure and force coefficients for solar panels, Journal of Wind Engineering and Industrial Aerodynamics, Vol. 125, Issue February 2014, 2014, pp. 195-206.

[5] Ferroudji F., Ouattas T., and Khélifi C., Design, Modelling and Finite Element Static Analysis of a New Two Axis Solar Tracker Using SolidWorks/COSMOSWorks, Applied Mechanics and Materials, Vol. 447, Issue. 2013, pp.738-743.

[6] Lates M.T., Mechanical Behaviour Analysis with the Finite Elements Method of Solar Collector ' s Tracking Systems, Wseas transactions on applied and theoretical mechanics, Vol. 3, Issue 7, 2008, pp. 244-253.

[7] Vellcu R., Lates M., Wind Load Cases in the Design of the Platform of an Azimuthal. ANNALS OF THE ORADEA UNIVERSITY Fascicle of Management and Technological Engineering, Vol. XXIII (XIII), Issue 1, 2014, pp.1-4.

[8] Al-Rashidi A. and El-Hamalawi A., A Performance Study of Fixed, Single-Axis and Dual-Axis Photovoltaic Systems in Kuwait, World Academy of Science, Engineering and Technology International Journal of Electrical, Computer, Energetic, Electronic and Communication Engineering, Vol. 10, Issue 9, 2016, pp. 1203-1207.

[9] Al-Rashidi A., A Technical, Economic and Environmental Evaluation Study of Utilising Fixed, Single and Dual-Axis Solar Photovoltaic Systems in Boubyan and Failaka Islands in Kuwait, American Journal of Engineering and
Applied Sciences, Vol. 12, Issue 4, 2019, pp. 495-502.

[10] Al-Rashidi A., Feasibility Study of Utilising 1 MW Grid-Connected Solar Photovoltaic System in Boubyan and Failaka Islands, International Conference on Innovative Applied Energy, Oxford, United Kingdom, 2019.

[11] Al-Rashidi A., Investigating the Feasibility of Solar Photovoltaic Systems in Kuwait, thesis, Loughborough University, 2017.

[12]Hibbeler R. C., MECHANICS OF MATERIALS, 8th ed, Prentice Hall, 2010.

[13] COMSOL Multiphysics, Solar Panel in Periodic Flow, URL www.comsol.com, 2020.

[14] Kuwait Institute for Scientific Research (KISR), Kuwait National Meteorological Network, 2015.

[15] Neelamani S. and Al-awadi L., Extreme Winds in Kuwait Including the Effect of Climate Change, Fundamental and Advanced Topics in Wind Power, 2012, pp. 89-112.

[16] American Society of Civil Engineers (ASCE), Minimum Design Loads for Buildings and Other Structures (ASCE 7-10), 2013.

[17] Abdullah W., Ramasamy A., Talaat A., and Alotaibi S, Verification of the preloading design of soft clay with prefabricated vertical drains by full-scale field instrumentation and numerical modelling, International Journal of Geotechnical Engineering, Vol. 13, Issue 1, 2019, pp. 92-101.

[18] Lalanne C., Mechanical vibration and shock analysis, fatigue damage, John Wiley \& Sons, 2010.

[19] Khelifi C. and Ferroudji F., Stress and fatigue analyses under wind loading of the dual axis sun tracking system via finite element analysis, Journal of Mechanical Engineering and Sciences, Vol. 10, Issue 2, 2016, pp. 20082015.

[20] Stephens R.I., Fatemi A., Stephens R.R. and Fuchs H.O., Metal fatigue in engineering, John Wiley \& Sons, 2000.

[21] Boyer H.E., Atlas of Fatigue Curves, Asm International, 1985.

[22] Davis J.R., Mills K.M., and Lampman S.R., Metals handbook, Properties and selection: Irons, steels, and high-performance alloys, $10^{\text {th }}$ ed, ASM International, 1990.

Copyright (c) Int. J. of GEOMATE. All rights reserved, including the making of copies unless permission is obtained from the copyright proprietors. 